\title{
Expanded reproductive carrier screening-how can we do the most good and cause the least harm?
}

\author{
Martin B. Delatycki ${ }^{1,2} \cdot$ Nigel Laing ${ }^{3,4} \cdot$ Edwin Kirk $^{5,6,7}$
}

Received: 30 January 2019 / Accepted: 31 January 2019 / Published online: 13 February 2019

(c) European Society of Human Genetics 2019

In this issue of the journal Schuurmans et al. [1] report on the outcome of a pilot study of general practitioners in northern Netherlands offering "couple" expanded reproductive carrier screening. Screening was offered by 13 general practitioners to 4295 females. Eligibility required that the woman was aged between 18 and 40, had a male partner, and the couple were planning a pregnancy but were not pregnant at the time. One hundred and thirty couples were counselled by the trained general practitioners of whom 119 couples had screening. Ninety-one per cent of women were satisfied with the counselling they received, 97\% were identified as having sufficient knowledge to make a decision about screening, and $88 \%$ had a positive attitude towards screening. The authors conclude, based on this pilot, that offering screening through general practitioners is feasible but that to expand this pilot to a whole population would require considerable resources to train general practitioners and that funding is required to pay general practitioners for the amount of time necessary to perform this task which took on average $20 \mathrm{~min}$.

Carrier screening to identify heterozygotes for autosomal recessive and $\mathrm{X}$-linked recessive conditions has been possible since the 1970s [2]. Initial screening was for

Martin B. Delatycki

martin.delatycki@vcgs.org.au

1 Victorian Clinical Genetics Services, Parkville, VIC, Australia

2 Murdoch Children's Research Institute, Parkville, VIC, Australia

3 Centre for Medical Research, University of Western Australia, Nedlands, WA, Australia

4 Harry Perkins Institute of Medical Research, Nedlands, WA, Australia

5 Sydney Children's Hospital, Randwick, NSW, Australia

6 New South Wales Health Pathology, Randwick, NSW, Australia

7 School of Women's and Children's Health, University of New South Wales, Randwick, NSW, Australia haemoglobinopathies and Tay-Sachs disease. Screening for carrier status for these conditions was possible because carriers have differences to non-carriers in haematologic and biochemical markers, respectively. As the genes associated with an increasing number of conditions were identified, carrier screening by genetic testing became possible in the late 1980s. Examples of screening by genetic testing includes screening for cystic fibrosis, spinal muscular atrophy, and fragile $\mathrm{X}$ syndrome.

When screening is for one or few conditions, the results of testing are provided to each person tested. It is now possible to test for almost every autosomal recessive and Xlinked recessive condition, for which the genetic basis is known, through massively parallel sequencing, so-called expanded carrier screening. Such screening will identify the majority of individuals as a carrier of at least one condition. This raises issues of the practicality of providing every screened individual with information about the condition(s) for which they are carriers. A solution to this concern is "couple screening". In couple screening, both members of the couple are screened and provided with one of two results. Where both members of the couple are carriers of the same autosomal recessive condition or the woman is a carrier of an X-linked condition, and thus the couple have a high chance of having a child with that condition, the couple are provided information about their carrier state for those conditions. If the couple are not both carriers of the same autosomal recessive condition and the woman is not a carrier of an X-linked condition the couple are informed that they have a low chance of having a child with any of the conditions screened for. They are not provided with their individual carrier status results for autosomal recessive conditions.

The advantage of couple screening is that it markedly reduces the time required for genetic counselling for screening programmes. A recent study found that a median of $64 \mathrm{~min}$ is required per person to provide the results of expanded carrier screening [3]. The two major disadvantages of couple screening are that it misses the 
opportunity for cascade screening and if a couple splits up they may be unaware of the fact that a subsequent relationship may be at risk of having a child with one of the conditions for which screening is done. As highlighted by the study of Schuurmans and colleagues, even for well trained and highly motivated general practitioners, face to face pretest counselling can also be labour-intensive and may not be possible at population scale. The Netherlands has an annual birthrate of approximately 170,000. Assuming a fertility rate of 1.7 , this equates to 100,000 first pregnancies each year. If all were to be preceded by a $20-$ min consultation with a general practitioner, the time of 16 general practitioners, working $40 \mathrm{~h}$ weeks and doing no other work, would be required to meet the demand.

The study by Schuurmans and colleagues is an important one, as expanded carrier screening is being offered to more individuals and couples and more conditions are being included in screening panels [1]. It is likely that in the not too distant future, exome sequencing or whole-genome sequencing will be performed to identify carrier status for over 1000 genes. If this were to become standard practice, it would be impractical to provide post-test counselling to all carriers. Couple screening therefore is a very attractive model. If couple screening is introduced, it will be imperative that couples are made aware that if they procreate with a different partner, a new test is required for the new partnership.

The best time for reproductive carrier screening is preconception. This allows for the greatest number of reproductive options for couples with a high chance of having a child with one of the conditions for which screening is done. This includes preimplantation genetic diagnosis using in vitro fertilisation in addition to prenatal diagnosis. Nevertheless the majority of individuals who have carrier screening are pregnant at the time of screening [4]. The idea of general practitioners being at the forefront of such screening programmes is attractive to maximise exposure to preconception screening since general practitioners see many individuals and couples in the period prior to conception. Nevertheless, screening in early pregnancy needs to be available since this is the time that many individuals and couples will first consider having screening. In addition, in a programme that is based around couple screening, the needs of pregnant women where there is no access to screening the male partner (for example, in the setting of anonymous sperm donation) need to be taken into account. Options include screening for X-linked conditions and for the most common recessive conditions such as cystic fibrosis and spinal muscular atrophy. If the woman is found to be a carrier of an X-linked condition or a common autosomal recessive condition, she could then have the option of prenatal diagnosis.

The extraordinary advances in genomic testing are already having a major impact on pre-pregnancy and pregnancy care and these will only increase as the technology improves and the costs reduce. Innovative methods of dealing with the educational requirements and the enormous amount of data generated will be required. The huge task of educating ever increasing numbers of individuals and couples about expanded carrier screening requires innovative approaches. Companies are producing mobile telephone applications and chatbots [5] to maximise education and minimise workloads. Ongoing creativity is required to maximise informed decision making by individuals and couples about the choice of whether or not to have expanded carrier screening.

\section{Compliance with ethical standards}

Conflict of interest The authors declare that they have no conflict of interest.

Publisher's note: Springer Nature remains neutral with regard to jurisdictional claims in published maps and institutional affiliations.

\section{References}

1. Schuurmans J, Birnie E, van den Heuvel L, Plantinga M, Lucassen A, van der Kolket DM, et al. Feasibility of couple-based expanded carrier screening offered by general practitioners Eur J Hum Genet. https://doi.org/10.1038/s41431-019-0351-3. 2019.

2. Delatycki MB. Population screening for reproductive risk for single gene disorders in Australia: now and the future. Twin Res Hum Genet. 2008;11:422-30.

3. Lynch FL, Himes P, Gilmore MJ, Morris EM, Schneider JL, Kauggman TL, et al. Time costs for genetic counseling in preconception carrier screening with genome sequencing. J Genet Couns. 2018;27:823-33.

4. Archibald AD, Smith MJ, Burgess T, Scarff KL, Elliott J, Hunt CE, et al. Reproductive genetic carrier screening for cystic fibrosis, fragile $\mathrm{X}$ syndrome, and spinal muscular atrophy in Australia: outcomes of 12,000 tests. Genet Med. 2018;20:513-23.

5. Nazareth S, Simmons E, Snir M, Shohat M, Goldberg J. Use of a chatbot to offer pre-test education for expanded carrier screening. American College of Medical Genetics; 2019. https://acmg.expopla nner.com/index.cfm?do=expomap.sess\&event_id=13\&session_id $=$ 8836 